\title{
An improved separator box for Artemia nauplii and other phototactic invertebrates
}

\author{
G. Persoone \& P. Sorgeloo\%* \\ Laboratory for Ecology, Rijksuniversiteit Gent; Gent, Belgium
}

EXTRAIT: Une boite de séparation plus efficiente pour les larves d'Artemia et autres invertébrés phototactiques. Un appareil cylindrique, simple à construire, est décrit, permettant la séparation des larves d'Artemia de leurs coquilles vides ou des oeufs non éclos, et une récupération facile des nauplii. Il peut en outre servir à séparer d'autres organismes phototactiques, soit de particules inertes, soit d'organismes non phototactiques. Par sa construction cylindrique les «effets de coin» sont annulés, ce qui assure une séparation bien plus efficiente qu'avec les appareils conventionnels.

\section{INTRODUCTION}

Being one of the very few organisms which are constantly available in the form of "dried cysts" (Davereier), the brine shrimp Artemia salina has been intensively used as a most interesting test organism for fundamental as well as for applied research (NImura 1967).

As the nauplii (which hatch a few days after immersion of the eggs in sea water) constitute an excellent food for a variety of invertebrates and fish larvae, wintering eggs of brine shrimp (California and Utah, U.S.A.) are sold all over the world.

The positive phototactic behaviour of the nauplii is used to separate them from empty shells and unhatched "eggs". However, with most of the methods described earlier, separation is qualitatively and quantitatively far from being optimal.

Shelbourne et al. (1963) constructed an Artemia salina hatching box and separator, which consists of a non-transparent box divided into two halves (an incubator and a separator compartment) by a dark partition which can slide up and down. The eggs are put in the incubator at an optimal density of $0.75 \mathrm{~g}$ eggs per litre of sea water at $23^{\circ} \mathrm{C}$. 44 hours later, by slightly raising the partition and covering the incubator with a lid, the hatched nauplii migrate into the illuminated separator compartment. The larvae can then be harvested from the latter with plankton gauze netting.

Shelbourne (in: Costlow 1969) admits that their system is not entirely satisfactory, "... separation is often poor and output not too good". Conducting experiments with the above mentioned apparatus (Sorgeloos 1971), one of us found that the

" "Navorsingsstagiair" at the Belgian "National Fund for Scientific Research". 
major reason for poor success in separation lies in the "corner seeking behaviour" of the larvae. So we decided to construct a cylindrical hatching and separator box which, besides avoiding the "corner effect", has the advantage that recovery of the larvae is much easier because the contents of the separator compartment can be poured out without any risk of contamination by shells or unhatched eggs from the hatching compartment.

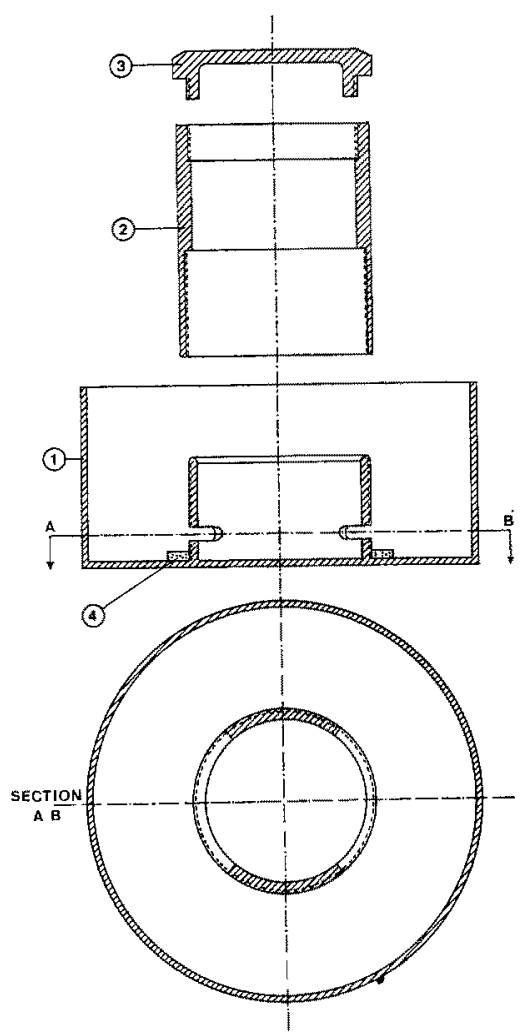

Fig. 1: Lateral and section views of the different parts of the box. (1) Cylindrical non-transparent box (PVC) with internal separation cylinder containing slits and screw-thread. (2) Hatching cylinder with internal screw-thread at top and bottom. (3) Lid with external screwthread. (4) Rubber ring

\section{DESCRIPTION OF THE APPARATUS}

The apparatus (Figs 1 and 2), entirely made of non-transparent PVC, consists of an open cylindrical box (1) in the middle of the bottom of which a short cylinder with external screw-thread is glued (the separation cylinder). About $1 \mathrm{~cm}$ above the bottom, this internal tube is almost split in two parts by two horizontal slits $(5 \mathrm{~mm}$ high).

A second cylinder (2) (the hatching cylinder) slightly higher than the open box 
and with internal screw-thread at the top and at the bottom part, can be screwed on the separation cylinder.

A rubber ring (4) glued on the bottom of the box ensures a tight separation between both compartments. The hatching cylinder can be closed with a lid (3) screwed to its top.

Though the dimensions of the device can be selected according to the number of eggs to be hatched and separated, we advise to take into account the relative proportions of the different parts.

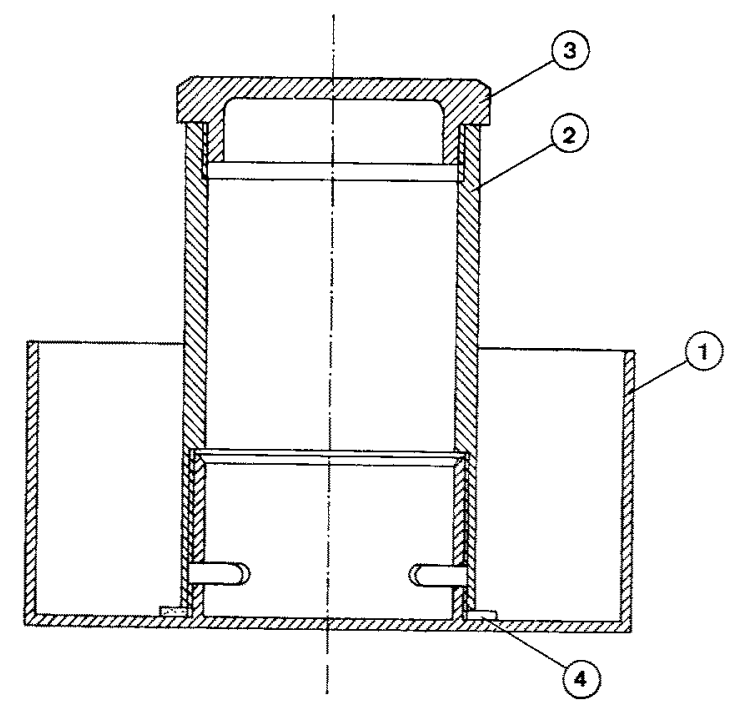

Fig. 2: Lateral view of assembled device. (1) Cylindrical box. (2) Hatching cylinder screwed on separation cylinder. (3) Lid screwed on hatching cylinder. (4) Rubber ring glued to bottom of box

The apparatus which we presently use has the following dimensions: Box (1): diameter $150 \mathrm{~mm}$, height $70 \mathrm{~mm}$; Hatching tube (2): diameter $65 \mathrm{~mm}$, height $90 \mathrm{~mm}$; Separator tube (3): diameter $65 \mathrm{~mm}$, height $50 \mathrm{~mm}$; Slits: length $60 \mathrm{~mm}$, height $5 \mathrm{~mm}$.

\section{OPERATION}

The box is filled with sea water to $\% / 3$ of its volume and the hatching cylinder tightly screwed to the separation cylinder. The water level is equal in both compartments: the interior one or "hatching cylinder" and the exterior one or "separator compartment".

Artemia salina eggs, in a concentration of approximately $400 \mathrm{mg} / 100 \mathrm{ml}$ water, are placed in the internal compartment. During the process of hatching, the eggs are kept in suspension by bubbling air through an airstone on the bottom of the hatching cylinder. 
According to literature, optimal hatching conditions are: $28^{\circ}$ to $30^{\circ} \mathrm{C}$ (BoONE \& BaAs-Becking 1931) and 10 to 50\% salinity (Jennings \& Whitaker 1941). The eggs should be kept in motion (Teramoto \& Kinoshita 1961).

After most of the eggs have hatched (time span depends on many variables such as geographic origin or age of the batch), the airstone is lifted out and the hatching cylinder partly unscrewed till the slits are freed. The hatching cylinder must then be covered with its lid and the separator box illuminated by a strong light placed above the device. Within half an hour most of the nauplii migrate through the slits from the dark hatching cylinder into the illuminated external compartment. By rescrewing the hatching cylinder down to the bottom, the two compartments are completely separated and the larvae can be recovered by pouring out the contents of the separation chamber without risk of contamination with debris from the tightly closed hatching cylinder.

\section{DISCUSSION}

Although this device was primarily constructed for separating Artemia nauplii from their empty egg shells, it is clear that its use can be extended to other purposes: for example, separation of other phototactic organisms (such as Dapbnia species) either from their exuviae, empty egg shells, detritus, or even other organisms without phototactic behaviour.

Several items of the described separator box are used daily in our laboratory giving up to $95 \%$ separation of Artemia salina nauplii. Experiments are in progress to determinate the influence of the density of larvae on the percentage of migration of the larvae.

As concerns the problem of hatching eggs of the brine shrimp, we should like to emphasize that we use the apparatus described only as separator box and that we prefer to hatch the eggs in a simple but convenient "circulation tube" (Sorgeloos \& Persoone 1972). The reason for this is that in the hatching and separator box it is not possible to avoid partial sedimentation of the eggs in the internal hatching compartment. Moreover, violent air bubbling which keeps most eggs in suspension, unfortunately, has a deleterious effect on the sensitive nauplii (FORSTER \& WICKINS 1967, Greve 1968, Rice \& Williamson 1970).

\section{SUMMARY}

1. A simple cylindrical hatching and separator box is described for Artemia salina nauplii (and other phototactic invertebrates), in which the "corner seeking effect" responsible for poor separation is avoided, and from which nauplii can be recovered very conveniently.

2. Separation is achieved by partly unscrewing an internal and closed cylinder from its fixed counter-part glued to the bottom of the box, till two slits are freed through which the nauplii migrate from the darkened internal hatching cylinder into the 
illuminated exterior compartment. Rescrewing the former cylinder separates the larvae from debris and unhatched eggs.

\section{LITERATURE CITED}

Boone, E. \& BaAs-Becking, L. G. M., 1931. Salt effects on eggs and nauplii of Artemia salina L. J. gen. Physiol. 14, 753-763.

Costlow, J. D. (Ed.), 1969. Marine Biology. Vol. 5. Gordon \& Breach, New York, 606 pp.

Fonster, J. R. M. \& Wickins, J. F., 1967. Experiments in the culture of the prawn Palaemon serratus (Pennant). Coun. Meet. int. Coun. Explor. Sea (= C.M. - I.C.E.S.) E. 13.

Greve, W., 1968. The "planktonkreisel", a new device for culturing zooplankton. Mar. Biol. 1, 201-203.

Jennings, R. H. \& Whitaker, D. M., 1941. The effect of salinity upon the rate of excystment of Artemia salina. Biol. Bull. mar. biol. Lab., Woods Hole, 80, 194-201.

Nimura, Y., 1967. Biology of the brine shrimp - Review. Bull. Jap. Soc. scient. Fish. 33, $690-702$.

Rice, A. L. \& Wrlliamson, D. I., 1970. Methods for rearing larval decapod Crustacea. Helgoländer wiss. Meeresunters. 20, 417-434.

Shelbourne, J. E., Riley, J. D. \& Tacker, G. T., 1963. Marine Fish culture in Britain. I. Plaice rearing in closed circulation at Lowestof, 1957-1960. J. Cons. perm. int. Explor. Mer 28, 50-69.

Sorgeloos, P., 1971. De kweekproblematiek bij invertebraten: experimenten met Artemia salina L. Thesis, Gent. (Unpubl.)

- \& Persoone, G., 1972. Three simple culture devices for aquatic invertebrates and fish larvae with continuous recirculation of the medium. Mar. Biol. (In press).

Teramoto, K. \& Kinoshita, S., 1961. Some informations on the culture of Artemia. Bull. Jap. Soc. scient. Fish. 27, 801-804.

First author's address: Dr. G. Persoone

Laboratory for Ecology

Rijksuniversiteit Gent

Ledeganckstraat 35

Gent

Belgium 